\title{
BMJ Prevalence and audiological features open in carriers of GJB2 mutations, c.35delG and c.101T>C (p.M34T), in a UK population study
}

\author{
Amanda Hall, ${ }^{1}$ Marcus Pembrey, ${ }^{2}$ Mark Lutman, ${ }^{3}$ Colin Steer, ${ }^{2}$ \\ Maria Bitner-Glindzicz ${ }^{4}$
}

To cite: Hall A, Pembrey M, Lutman $\mathrm{M}$, et al. Prevalence and audiological features in carriers of GJB2 mutations, c.35delG and c.101T>C (p.M34T), in a UK population study. BMJ Open 2012;0:e001238/.

doi:10.1136/bmjopen-2012001238

- Prepublication history and additional material for this paper are available online. To view these files please visit the journal online (http://dx. doi.org/10.1136/bmjopen2012-001238).

Received 2 April 2012 Accepted 29 June 2012

This final article is available for use under the terms of the Creative Commons Attribution Non-Commercial 2.0 Licence; see

http://bmjopen.bmj.com

${ }^{1}$ Centre for Hearing and Balance Studies, University of Bristol, Bristol, UK

${ }^{2}$ Department of Social and Community Medicine, University of Bristol, Bristol, UK

${ }^{3}$ Institute of Sound and Vibration Research, University of Southampton,

Southampton, UK

${ }^{4}$ Institute of Child Health, UCL, London, UK

Correspondence to Amanda Hall, Centre for Hearing and Balance Studies, 8-10 Berkeley Square, Bristol, BS8 1HH, UK; amanda.hall@bristol.ac.uk

\begin{abstract}
Objectives: To determine the carrier rate of the GJB2 mutation c.35delG and c.101T>C in a UK population study; to determine whether carriers of the mutation had worse hearing or otoacoustic emissions compared to non-carriers.
\end{abstract}

Design: Prospective cohort study.

Setting: University of Bristol, UK.

Participants: Children in the Avon Longitudinal Study of Parents and Children. 9202 were successfully genotyped for the c.35delG mutation and c.101>T and classified as either carriers or non-carriers.

Outcome measures: Hearing thresholds at age 7, 9 and 11 years and otoacoustic emissions at age 9 and 11 . Results: The carrier frequency of the c.35delG mutation was $1.36 \%(95 \% \mathrm{Cl} 1.13$ to 1.62$)$ and $\mathrm{c} .101 \mathrm{~T}>\mathrm{C}$ was $2.69 \%(95 \% \mathrm{Cl} 2.37$ to 3.05$)$. Carriers of C.35delG and c.101T>C had worse hearing than non-carriers at the extra-high frequency of $16 \mathrm{kHz}$. The mean difference in hearing at age 7 for the c.35delG mutation was $8.53 \mathrm{~dB}$ $(95 \% \mathrm{Cl} 2.99,14.07)$ and $12.57 \mathrm{~dB}$ at age $9(95 \% \mathrm{Cl}$ 8.10, 17.04). The mean difference for $C .101 \mathrm{~T}>\mathrm{C}$ at age 7 was $3.25 \mathrm{~dB}(95 \% \mathrm{Cl}-0.25$ to 6.75$)$ and $7.61 \mathrm{~dB}(95 \%$ $\mathrm{Cl} 4.26$ to 10.96) at age 9. Otoacoustic emissions were smaller in the c.35delG mutation carrier group: at $4 \mathrm{kHz}$ the mean difference was $-4.95 \mathrm{~dB}(95 \% \mathrm{Cl}-6.70$ to $-3.21)$ at age 9 and $-3.94 \mathrm{~dB}(95 \% \mathrm{Cl}-5.78$ to -2.10$)$ at age 11. There was weak evidence for differences in otoacoustic emissions amplitude for c.101T>C carriers.

Conclusion: Carriers of the c.35delG mutation and c.101T>C have worse extra-high-frequency hearing than non-carriers. This may be a predictor for changes in lower-frequency hearing in adulthood. The milder effects observed in carriers of c.101T $>C$ are in keeping with its classification as a mutation causing mild/moderate hearing loss in homozygosity or compound heterozygosity.

\section{INTRODUCTION}

The human gap junction $\beta-2$ gene (GJB2) that encodes the protein connexin 26 was the first autosomal gene to be identified for non-syndromic deafness. ${ }^{1}$ Connexin 26 is

\section{ARTICLE SUMMARY}

Article focus

- To determine the carrier rate of the GJB2 mutation C.35delG and c.101T>C in a UK population study To compare hearing thresholds and otoacoustic emissions between carriers and noncarriers.

\section{Key messages}

- The carrier rate of the c.35delG mutation was $1.4 \%$ The carrier rate of $\mathrm{C} .101 \mathrm{~T}>\mathrm{C}$ was $2.7 \%$ Carriers of C.35delG and c.101T>C had worse hearing at $16 \mathrm{kHz}$ than non-carriers.

Strengths and limitations of this study

- A strength is the size of the study and that participants were unselected for hearing status $A$ limitation is sample attrition leading to possible loss of statistical power when comparing hearing between carriers and non-carriers.

- The study is generalisable to the white UK population only.

involved in recycling of potassium ions in the endolymph of the cochlea ${ }^{2}$ and mutations in this gene are by far the commonest cause of autosomal-recessive non-syndromic sensorineural hearing loss (NSSNHL) worldwide.

The mutation c.35delG is the most common mutation causing severe-profound deafness in Caucasian populations and accounts for approximately $70 \%$ of autosomal recessive NSSNHL. ${ }^{3}$ The c.35delG carrier rate was evaluated by Mahdieh and Rabbani ${ }^{5}$ who pooled data from 41 studies, including a review by Gasparini et at in which they estimated the carrier rate to be highest in Europe with a mean rate of $1.89 \%$. However within Europe, there was variation across countries with a higher rate of 2.48\% in Southern Europe compared with $1.53 \%$ in Northern Europe. ${ }^{5}$ This variation highlights the importance of knowing the carrier rate for individual countries. There 
are, however, relatively few data from the UK with Gasparini et at finding $0 / 119$ carriers in the UK arm of their European study. The high carrier rate of GJB2 mutations is of interest and some have suggested possible heterozygote advantage. ${ }^{7}$ Such an advantage would have to outweigh any negative biological effects on hearing.

There has also been interest in c.101T $>$ C (p.M34T) the effect of which on hearing is the subject of contention. c.101T $>$ C (p.M34T) has a higher carrier rate than c.35delG in Caucasian populations. A US study found 3/ 128 carriers, $^{9}$ giving a rate of $2.3 \%$ and Houseman et al ${ }^{10}$ found a carrier rate of $4.8 \%$ in the UK based on a small sample of 630 .

c.101T $>$ C (p.M34T) was first described as a dominant mutation $^{1}$ and subsequently as a recessive mutation. ${ }^{10-12}$ In vitro studies have shown that GJB2: p.M34T is correctly synthesised, locates to the cell membrane normally, but shows impaired intercellular coupling as judged by transfer of dyes between neighbouring cells through the gap junctions. There are also observations that there is disturbed oligomerisation of GJB2:p.M34T connexins. $^{13-15}$ One would therefore expect an effect on the cochlea and on hearing. Some studies have demonstrated dominant negative effects of the mutant (p.M34T) on wild-type connexins ${ }^{15}{ }^{16}$ and yet it is clear from human genetic studies that this is not a dominantly acting mutation. Indeed many examples exist where homozygosity for p.M34T/p.M34T or compound heterozygosity p.M34T/c.35delG is associated with normal hearing $^{17-19}$ or a significantly milder hearing loss than that associated with truncating and even other nontruncating mutations of GJB2. ${ }^{10-12} 20$

Previous studies of hearing in GJB2 mutation carriers identified through genetic testing have shown conflicting results, summarised in supplementary table S1. All of these are small studies often based on ascertainment of carriers as the parents or relatives of children with severe/ profound deafness. Morell et $a l^{21}$ showed no/minor differences in the pure-tone audiograms of c.35delG carriers compared to controls, as did Engel-Yeger et $a l^{22} 23$ Conversely, Franzé et $a l^{24}$ showed worse high-frequency hearing thresholds in c.35delG carriers compared to controls. Using otoacoustic emissions (OAE), perhaps a more sensitive measure of hearing, carriers showed reduced amplitude OAE compared to controls, particularly for the high frequencies. Amplitude differences ranged from $5 \mathrm{~dB}$ across $1-4 \mathrm{kHz}^{21}$ to $1-2 \mathrm{~dB}$ across $1-10 \mathrm{kHz}^{22}{ }^{23}$ It has also been suggested that carriers of GJB2 mutations may be at greater risk of susceptibility to noise damage. ${ }^{25}$ However, a study of over 3000 participants found no increased susceptibility to age or noise exposure in c.35delG carriers compared to non-carriers. ${ }^{26}$

The relationship between genotype and phenotype in those carrying c.101T $>\mathrm{C}$ ( p.M34T) is even less clear, but of great interest given the high carrier rate. To our knowledge, there have been no population studies examining the hearing of c.101T $>$ C (p.M34T) carriers. However, studies of families with hearing loss have shown a varying effect of c.101T>C (p.M34T) on hearing. Bicego et $a l^{15}$ studied seven families with c.101T $>$ C (p.M34T) and hearing impairment. Within these families, there were 11 c.101T $>$ C (p.M34T) heterozygotes of which 5 had hearing loss. However, in several of these families, c.101T $>$ C ( p.M34T) did not segregate with hearing loss and some families appeared to have had dominantly inherited hearing losses.

In addition, these studies were all conducted on adults and it is not clear as to when in the life course these differences might arise. There is thus a need to accurately determine the UK carrier rate for GJB2 mutations and to further investigate the audiological profile of carriers within a population to determine whether previously found differences in hearing and OAE in adults are present in childhood. The aims of this study were first to determine the carrier rate of c.35delG mutations and c.101T $>$ G (p.M34T) in a large UK prospective population, the Avon Longitudinal Study of Parents and Children (ALSPAC) and second to compare hearing thresholds up to $16 \mathrm{kHz}$ and transient evoked OAEs in carriers of the GJB2 mutations c.35delG and c.101T $>C$ with non-carriers at age 7,9 and 11 years age. These issues have not been adequately addressed in the literature using a prospective study design with a large sample of participants unselected for hearing or genetic status.

\section{MATERIALS AND METHODS}

\section{Avon Longitudinal Study of Parents and Children}

This study uses data from ALSPAC, a large UK prospective population study of child development. ALSPAC recruited 14541 pregnant women resident in Avon, UK with expected dates of delivery 1 April 1991-31 December 1992. A wide range of information was collected on the mothers and their offspring, including detailed information about the mother during pregnancy, birth and medical history of the child, repeat physical and psychological measures of the child and educational outcomes. ${ }^{27}$ The profile of the cohort has been recently described $;^{28}$ of relevance to this study is the ethnicity of the children enrolled within ALSPAC who were predominantly white $(96.09 \%)$. The follow-up and attrition rate of the enrolled sample over time are also described. ${ }^{28}$ For further general information about ALSPAC, see http://www.bristol.ac.uk/alspac/.

From age 7 , the whole cohort was invited to attend a regular half day assessment 'Focus clinic' at the University of Bristol. As part of these clinics, blood samples were obtained for DNA analysis and at three clinics, hearing was assessed.

Ethical approval for the study was obtained from the ALSPAC Law and Ethics Committee and the Local Research Ethics Committees.

\section{DNA analysis}

DNA was extracted from cord blood and blood samples collected at Focus clinics. ${ }^{29}$ DNA from the ALSPAC 
cohort was screened by KBioScience following successful 'blind' validation of the assay using known positive and negative controls. Single-nucleotide polymorphism genotyping for the presence of both c.101T $>\mathrm{C}$ and c.35delG was performed by competitive allele PCR (KASPar) and TaqMan genotyping assays (www.kbioscience.co.uk/ genotyping/genotyping-chemistry.htm).

\section{Hearing and middle-ear measures}

At age 7, 9 and 11 years, children were assessed with pure-tone audiometry using Kamplex AD12 and GSI 61 audiometers at age 7, and a GSI 61 audiometer at age 9 and 11, with TDH 39 headphones, calibrated to ISO $389 .^{30}$ Air conduction thresholds were measured at $0.5-8 \mathrm{kHz}$, and bone conduction thresholds at $0.5-4 \mathrm{kHz}$ according to the British Society of Audiology recommended procedure for audiometry. ${ }^{31}$ At age 7 and 9, extra-high-frequency hearing thresholds were measured at $16 \mathrm{kHz}$ using the GSI 61 audiometer with circumaural HDA200 headphones. The $16 \mathrm{kHz}$ threshold was only measured where time permitted. Tympanometry was measured using a Kamplex AT2 tympanometer at age 7 and a GSI 38 tympanometer at age 9 and 11 years.

Measures at age 7 were taken in a quiet room and at 9 and 11 in a sound-treated booth. All tests were carried out by qualified audiologists or testers specially trained for this purpose. All staff underwent regular audits to assess their reliability on audiometry. Testers were blind to the results of previous hearing tests when performing audiometry and to the genetic status of the children. If a hearing loss was measured at the Focus clinic, parents were given a copy of the results and advised to consult their child's general physician.

\section{Otoacoustic emissions}

At age 9 and 11 years, transient evoked otoacoustic emissions were recorded using the Otodynamics ILO92 system. Click stimuli were presented at a gain of $-10.5 \mathrm{~dB}$ and $-19.5 \mathrm{~dB}$ (re: reference click at $\sim 80 \mathrm{~dB}$ sound pressure level (SPL)) and recordings made in the linear mode. These settings were used as lower-level stimuli may be more sensitive to changes and differences in cochlear function. ${ }^{32}$

Analysis of OAE waveforms here concentrates on the measure that is conventionally named as response, which is the SPL of the recorded components that are common to the two interleaved averages obtained during recording, conventionally denoted by $\mathrm{A}$ and $\mathrm{B}$. Analogous to the way that the power of a signal is obtained mathematically by summating across frequency the product of the Fourier transform of the signal and its complex conjugate, the response measure is derived by summating across frequency the real part of the crossproduct of the Fourier transform of A and the complex conjugate of the Fourier transform of B. The real part contains only those components that are in phase in $\mathrm{A}$ and $\mathrm{B}$. This measure can simply be considered as an estimate of the OAE signal after removal of the noise. The response measure was obtained from the raw (unfiltered) recordings and also after filtering into frequency bands centred on 1, 2, 3 and $4 \mathrm{kHz}$. Each filter had a bandwidth of $1 \mathrm{kHz}$.

OAE amplitudes, as defined by the response measure, of the broadband wave and at $1,2,3$ and $4 \mathrm{kHz}$ were used as outcomes.

\section{Sociodemographic data}

Information on child sex (male/female), ethnicity (white/non-white), birthweight, gestation, maternal age and highest level of maternal education $(<16,16$ and $>16$ years) was available from medical records, clinic visits and parental self-completion questions. These data were used to describe the sociodemographics of the sample and to compare to those with no genetic and hearing data available.

The relationship of child sex and ethnicity with hearing and carrier status was investigated for possible confounding.

\section{Statistical analysis}

Univariate linear regression analyses were performed to analyse associations between carrier status (carrier of c.35delG mutation/non-carrier; carrier of c.101T $>$ C/ non-carrier) and hearing/OAE outcomes. Both genetic variables were included in the analyses to allow direct comparison of effect sizes. To increase the statistical power, right and left ear hearing thresholds and right and left OAE amplitude data were averaged for each participant. Analyses were performed using STATA V.11.0.

\section{RESULTS \\ Sample}

Genetic data were available on 9631 children of the whole cohort whose parents consented for biological samples to be taken at clinical visits. Of these 9631 samples, genotyping was successfully performed on 9202 samples (95.5\%). Their characteristics and how they compare with the rest of the ALSPAC cohort are shown in table 1 . As is typically seen in epidemiological studies the study sample was more advantaged than the rest of the cohort. There was an under-representation of non-white children and an overrepresentation of children from older, more educated mothers in the study sample. The children in the study sample also had a higher birthweight and a longer gestation period.

\section{Carrier rate}

The c.35delG and c.101T $>\mathrm{C}$ mutation rate is summarised in table 2. This shows a carrier rate of $1.36 \%(95 \%$ CI $1.13 \%$ to $1.62 \%$ ) for c.35delG and $2.69 \%$ (95\% CI $2.37 \%$ to $3.05 \%)$ for c. $101 \mathrm{~T}>\mathrm{C}$. Three cases, $0.03 \%(95 \%$ CI $0.006 \%$ to $0.09 \%$ ) were homozygous for c.101T $>$ C, see figure 1 for their audiograms. None of the participants carried both the c.35delG mutation and c.101T $>$ C. 
Table 1 Characteristics of the study sample compared with the remaining ALSPAC cohort

$\begin{array}{ccc}\begin{array}{l}\text { Sample with genetic information } \\ \text { (either } \mathbf{c . 3 5 d e l G} \text { or } \mathbf{c . 1 0 1 T}>\mathbf{C})(\mathbf{n}=\mathbf{9 2 0 2})\end{array} & \text { Rest of ALSPAC cohort }(\mathbf{n = 5 3 2 1 )} & \mathbf{p} \text { Value } \\ 51.85 & 50.78 & 0.215 \\ 4.33 & 6.43 & 0.000 \\ 3422.56(543.25) & 3339.68(582.17) & 0.000 \\ 39.44(1.81) & 39.30(2.10) & 0.000 \\ 28.48(4.83) & 27.15(5.06) & 0.000 \\ & & \\ 26.43 & 39.96 & 0.000 \\ 35.17 & 34.59 & \\ 38.43 & 35.38 & \end{array}$

\section{Sex (\% males)}

Child's ethnicity (\% non-white)

Mean birthweight (g) (SD)

Mean gestation (weeks) (SD)

Mean age of mother (years) (SD)

Maternal highest education

qualification (\%)

$<16$ years

16 years

$>16$ years

ALSPAC, Avon Longitudinal Study of Parents and Children.

政

There was no evidence of disequilibrium for either the c.35delG mutation $(\mathrm{p}=0.510)$ or $\mathrm{c} .101 \mathrm{~T}>\mathrm{C}(\mathrm{p}=0.334)$.

The sex and ethnicity characteristics of the sample were examined to determine whether these varied with both the carrier status and hearing thresholds, and thus could confound the results. Table 3 shows the sample characteristics according to carrier status. There was evidence of a weak association between child ethnicity and c.101T $>C$ carrier status $(p=0.026)$, but not between child ethnicity and average hearing thresholds at age 7 (left ear $\mathrm{p}=0.584$; right ear $\mathrm{p}=0.207$ ). There was no evidence of a sex difference between carriers and noncarriers for c.35delG $(\mathrm{p}=0.457)$ or $\mathrm{c} .101 \mathrm{~T}>\mathrm{C}(\mathrm{p}=0.387)$, although there was a relationship between sex and average hearing threshold with females having worse hearing than males (age 7 results: left ear $\mathrm{p}=0.076$; right ear $\mathrm{p}=0.000$ ). As carrier status and hearing thresholds did not vary consistently with sex and ethnicity, confounding is unlikely and therefore unadjusted statistical results are presented. Analyses were also performed excluding non-white children from the sample, and these gave essentially the same results, see supplemental tables S2 and S3.

\section{Hearing thresholds}

Hearing data from at least one time point were available on 97 out of 125 c.35delG carriers and 190 of 246 c.101T $>$ C carriers. Figure 2 displays the mean audiometric hearing thresholds for carriers and non-carriers at age 11 showing that the mean thresholds of the carrier and non-carrier groups were all within the normal range.
At age 7, 7774 of the cohort had hearing thresholds measured, at age 9 it was 7379 and at age 11 it was 7111 . As described for the genetic data, those children attending the Focus clinics were more likely to be advantaged compared with the rest of the cohort. Cases where both hearing threshold and genotype data were available were used in linear regression analysis to estimate the difference in hearing thresholds between carriers and noncarriers for each of the frequencies tested at age 7,9 and 11. Fewer than half the children had data for $16 \mathrm{kHz}$ due to time constraints. The c.35delG results of the regression analysis are shown in table 4 and the c.101T $>\mathrm{C}$ results in table 5. For the c.35delG mutation there was no evidence that the carriers had worse hearing thresholds at the conventional audiometric frequencies. However, at $16 \mathrm{kHz}$ there was strong evidence of a difference between the two groups with carriers having mean thresholds $8 \mathrm{~dB}$ worse than non-carriers at age 7 , increasing to $12 \mathrm{~dB}$ at age 9 .

For c.101T $>\mathrm{C}$ there was no evidence of a difference in hearing threshold between carriers and non-carriers at the conventional audiometric frequencies. At $16 \mathrm{kHz}$, there was evidence of worse hearing in the carrier group at age 9 and 11, with hearing $3 \mathrm{~dB}$ and $7 \mathrm{~dB}$ worse, respectively.

There was weak evidence that carrying the c.35delG mutation had a larger effect than c.101T $>\mathrm{C}$ on $16 \mathrm{kHz}$ hearing thresholds at age $9(\mathrm{p}=0.111)$ and $11(\mathrm{p}=0.079)$.

\section{Otoacoustic emissions}

OAE results obtained at the two different stimulus levels were analysed which showed essentially the same results

Table 2 Summary of GJB2 mutation carrier rate in Avon Longitudinal Study of Parents and Children

\begin{tabular}{lllll}
\hline & Homozygote $(\%)(\mathbf{n})$ & Heterozygote $(\%)(\mathbf{n})$ & Homozygote recessive & Total N \\
\hline c.35delG & G:G & G: - & & \\
& $98.63(9014)$ & $1.36(125)$ & $0(0)$ & 9139 \\
c.101T $>$ C & T:T & C:T & C:C & 9112 \\
& $97.27(8863)$ & $2.69(246)$ & $0.03(3)$ & \\
\hline
\end{tabular}



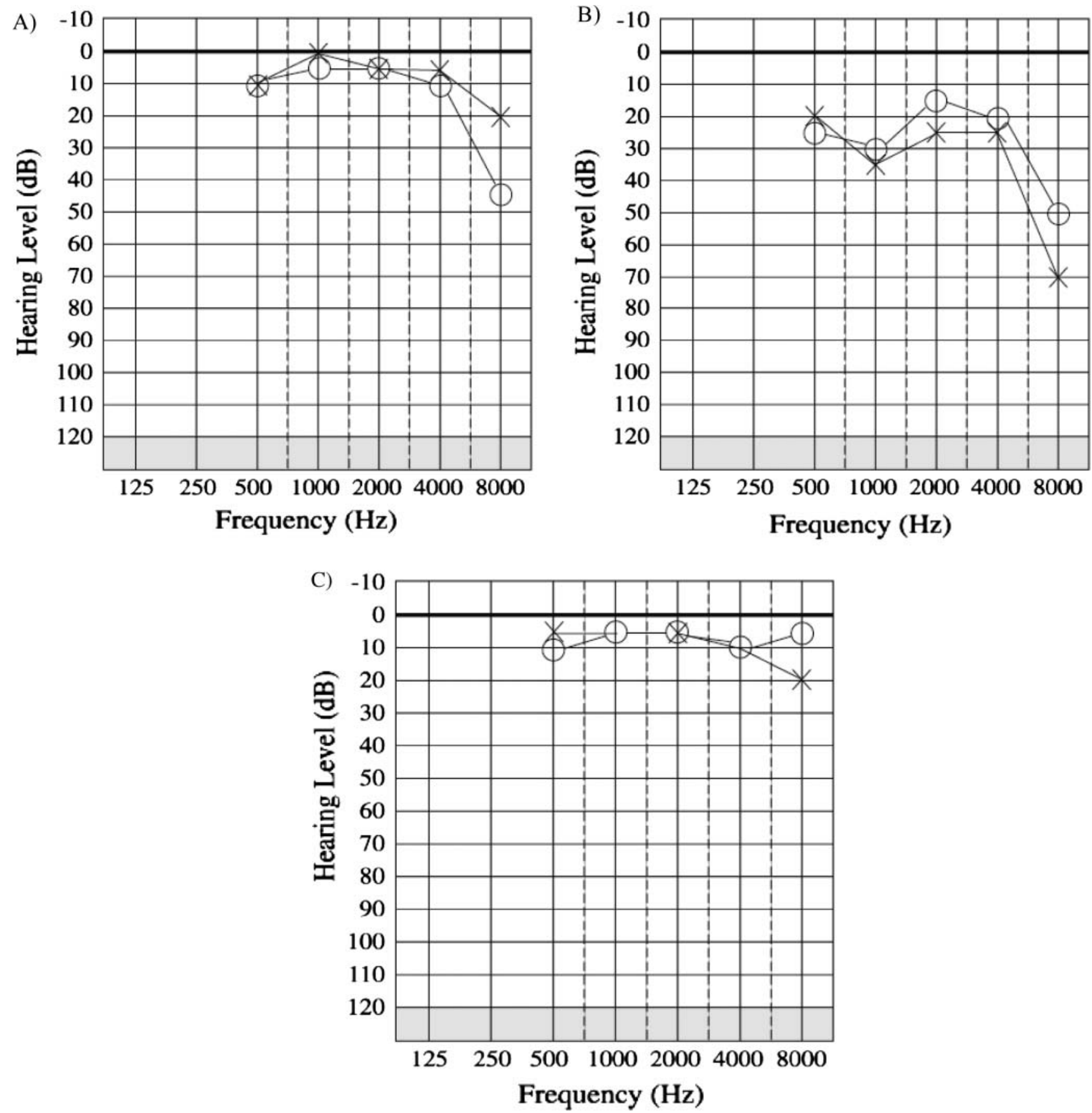

Figure 1 Audiograms of the three cases homozygous for $\mathrm{C} .101 \mathrm{~T}>\mathrm{C}$. The most recent and complete data are shown. (A) Case 1 at age $7,(B)$ case 2 at age $11,(C)$ case 3 at age 9.

for the lower and higher stimulus level settings. There was no evidence that lower stimulus settings were more sensitive to differences between groups and therefore only higher-stimulus-level results are shown.

Linear regression was used to compare the OAE amplitude across frequency for carriers and non-carriers. Table 6 shows the difference in amplitude at age 9 and 11 for the carriers and non-carriers (OAE were not recorded at age 7 ). At age 9 the c.35delG carrier group had smaller OAE amplitude compared to non-carriers across the frequency range, with the largest differences at 3 and $4 \mathrm{kHz}$. A similar pattern was observed at age 11, although the differences were slightly smaller.

For c.101T $>\mathrm{C}$ there was evidence of smaller OAE amplitude at $4 \mathrm{kHz}$ in the carriers at age 9 but not at 11 .

There was strong evidence that carrying the c.35delG mutation had a larger effect than c.101T $>\mathrm{C}$ on $\mathrm{OAE}$ amplitude at age $9(1 \mathrm{kHz}, \mathrm{p}=0.008 ; 2 \mathrm{kHz}, \mathrm{p}=0.011$; 
Hearing in carriers of $\mathrm{C.35delG}$ and $\mathrm{c.101T}>\mathrm{C}$

Table 3 Characteristics of the sex and ethnicity profile of carriers compared to non-carriers

\begin{tabular}{|c|c|c|c|c|}
\hline & \multicolumn{2}{|l|}{ c.35delG } & \multicolumn{2}{|l|}{ c. $101 \mathrm{~T}>\mathrm{C}$} \\
\hline & Non-carriers & Carriers & Non-carriers & Carriers \\
\hline \multicolumn{5}{|l|}{ Sex } \\
\hline n (\%) Males & 4674 (51.85) & $69(55.20)$ & 4607 (51.98) & $121(49.19)$ \\
\hline Child's ethnicity & & & & \\
\hline n (\%) Non-white & 342 (4.36) & $3(2.70)$ & $340(4.41)$ & $3(1.40)$ \\
\hline
\end{tabular}

$3 \mathrm{kHz}, \mathrm{p}=0.001$ and $4 \mathrm{kHz}, \mathrm{p}=0.001)$; the evidence was weaker at age $11(1 \mathrm{kHz}, \mathrm{p}=0.295 ; 2 \mathrm{kHz}, \mathrm{p}=0.046 ; 3 \mathrm{kHz}$, $\mathrm{p}=0.141$ and $4 \mathrm{kHz}, \mathrm{p}=0.009)$.

\section{DISCUSSION}

\section{Carrier rate}

This study is one of the largest of its type where children were unselected for hearing status and tested as part of a prospective population study of development. ALSPAC is broadly representative of the UK in terms of sociodemographics albeit with a lower proportion of ethnic minorities. The results reported here are likely to be broadly generalisable for a white UK population.

The prevalence of c.35delG carriers in the ALSPAC cohort was $1.36 \%$ (95\% CI $1.13 \%$ to $1.62 \%$ ) which is consistent with the figure of $1.53 \%$ (95\% CI $1.26 \%$ to
$1.83 \%$, calculated from data provided in the paper) given by Mahdieh and Rabbani ${ }^{5}$ for Northern Europe.

The prevalence of c. $101 \mathrm{~T}>\mathrm{C}$ in this study was $2.69 \%$ (95\% CI $2.37 \%$ to $3.05 \%$ ), which is double that of c.35delG and lower than the rate of $5.81 \%(95 \%$ CI $4.44 \%$ to $7.44 \%$, calculated from data provided in the paper) found in Estonia ${ }^{33}$ based on a sample size of 998. There were no cases carrying both the c.35delG mutation and c.101T $>\mathrm{C}$ in ALSPAC. Three cases $(0.03 \%)$ were homozygous for $\mathrm{c} .101 \mathrm{~T}>\mathrm{C}$. There was weak evidence that $\mathrm{c} .101 \mathrm{~T}>\mathrm{C}$ was less likely to be present in non-white children.

\section{Hearing thresholds and otoacoustic emissions in c.35delG carriers}

There was no effect of carrier status on hearing at the conventional audiometric thresholds examined at 7, 9
Figure 2 Mean audiograms at age 11. (A) c.35delG non-carriers, (B) c.35delG carriers, (C) c.101T>C non-carriers and (D) c.101T>C carriers.
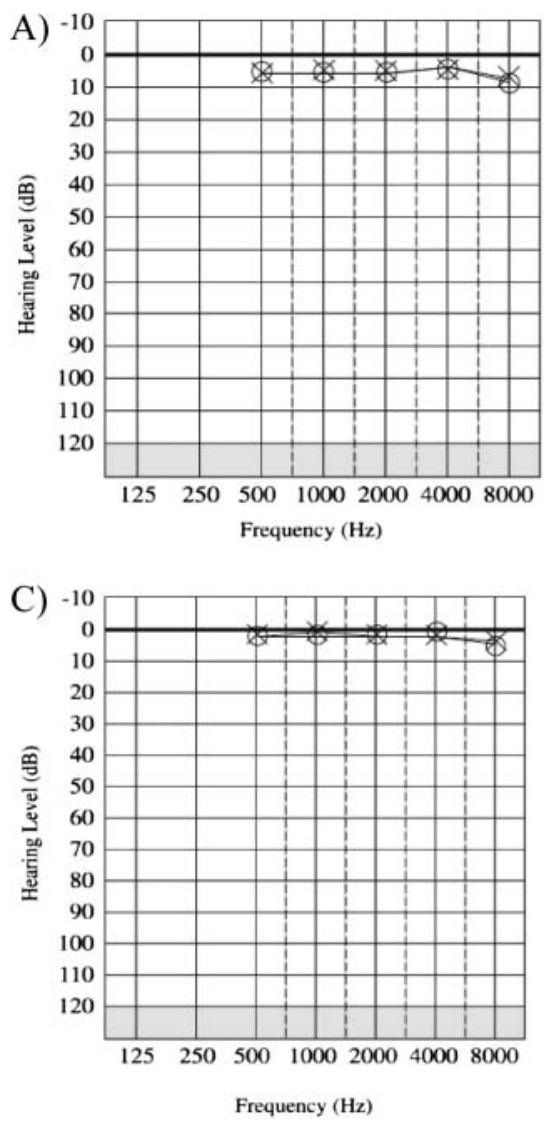
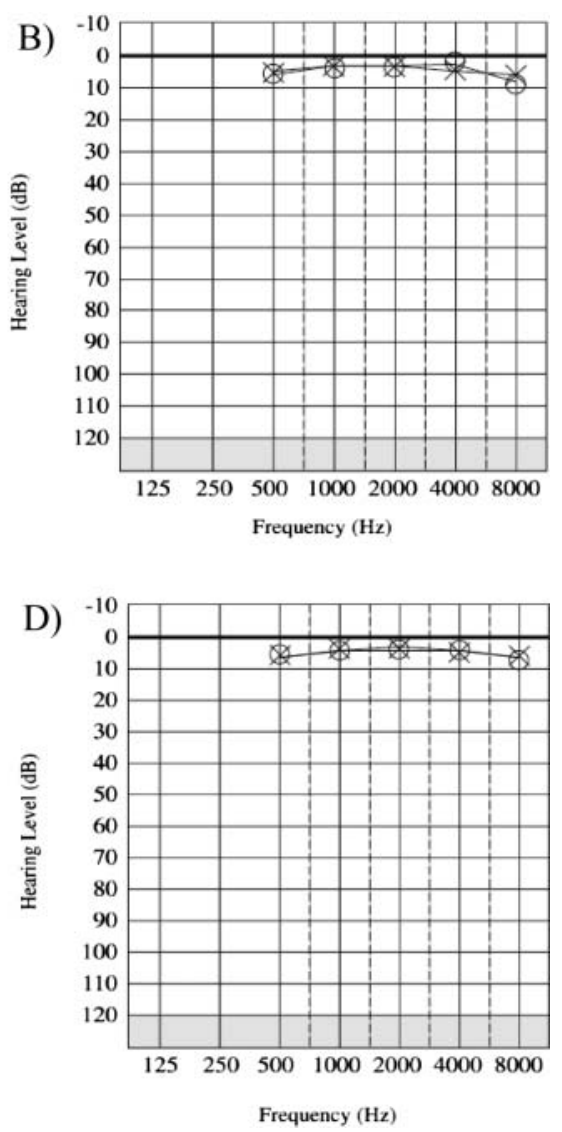
Table 4 Differences in hearing threshold between c.35delG carriers at age $7(n=80)$, age $9(n=81)$ and age $11(n=77)$ and non-carriers (unadjusted results)

\begin{tabular}{|c|c|c|c|c|c|c|c|c|c|c|}
\hline \multirow[b]{2}{*}{ Air or bone conduction } & \multirow[b]{2}{*}{ Frequency $^{*}(\mathrm{kHz})$} & \multicolumn{3}{|c|}{ Age 7} & \multicolumn{3}{|c|}{ Age 9} & \multicolumn{3}{|c|}{ Age 11} \\
\hline & & $\mathbf{N}$ & Coefficient dB† (95\% Cl) & $p$ Value & $\mathbf{N}$ & $\begin{array}{l}\text { Coefficient dB† } \\
(95 \% \mathrm{Cl})\end{array}$ & $p$ Value & $\mathbf{N}$ & $\begin{array}{l}\text { Coefficient dB† } \\
(95 \% \mathrm{Cl})\end{array}$ & $\mathrm{p}$ Value \\
\hline \multirow[t]{8}{*}{ Air } & 0.5 & 5892 & $0.01(-1.64$ to 1.67$)$ & 0.985 & 5697 & $0.04(-1.39$ to 1.47$)$ & 0.953 & 5429 & $-0.34(-1.81$ to 1.13$)$ & 0.650 \\
\hline & 1 & 6147 & $-0.16(-1.81$ to 1.48$)$ & 0.848 & 5783 & $0.68(-0.79$ to 2.14$)$ & 0.364 & 5473 & $-0.79(-2.23$ to 0.64$)$ & 0.277 \\
\hline & 2 & 6091 & $-0.58(-2.18$ to 1.01$)$ & 0.472 & 5782 & $-1.16(-2.59$ to 0.26$)$ & 0.112 & 5472 & $-1.28(-2.76$ to 0.18$)$ & 0.087 \\
\hline & $3 \ddagger$ & & & & & & & 5431 & $-1.26(-2.76$ to 0.24$)$ & 0.100 \\
\hline & 4 & 6144 & $0.14(-1.67$ to 1.97$)$ & 0.872 & 5782 & $-0.46(-2.10$ to 1.17$)$ & 0.578 & 5468 & $-0.75(-2.33$ to 0.83$)$ & 0.352 \\
\hline & $6 \ddagger$ & & & & & & & 5427 & $-0.67(-2.53$ to 1.19$)$ & 0.480 \\
\hline & 8 & 6119 & $0.63(-1.43$ to 2.70$)$ & 0.547 & 5675 & 0.34 (-1.63 to 2.33$)$ & 0.731 & 5388 & $-1.04(-3.00$ to 0.91$)$ & 0.297 \\
\hline & $16 \S$ & 2860 & 8.53 (2.99 to 14.07$)$ & 0.003 & 4166 & $12.57(8.10$ to 17.04$)$ & 0.000 & & & \\
\hline \multirow[t]{4}{*}{ Boneף } & 0.5 & & & & 5581 & $0.18(-1.27$ to 1.65$)$ & 0.800 & 5444 & $-0.92(-2.38$ to 0.53$)$ & 0.213 \\
\hline & 1 & 6001 & $-0.33(-1.86$ to 1.19$)$ & 0.669 & 5753 & $-0.75(-2.18$ to 0.66$)$ & 0.297 & 5449 & $-0.28(-2.02$ to 0.78$)$ & 0.388 \\
\hline & 2 & & & & 5593 & $-1.30(-2.93$ to 0.31$)$ & 0.113 & 5445 & $-1.32(-2.94$ to 0.29$)$ & 0.109 \\
\hline & 4 & 6107 & $-0.88(-2.36$ to 0.59$)$ & 0.243 & & & & & & \\
\hline
\end{tabular}

${ }^{*}$ Right and left ear average.

†A positive coefficient means that hearing threshold is higher (ie, worse) in the carrier group compared to the non-carriers.

¥Thresholds at 3 and $6 \mathrm{kHz}$ were measured at age 11.

§Thresholds at $16 \mathrm{kHz}$ were measured at age 7 and 9

IBone conduction thresholds were measured at 1 and $4 \mathrm{kHz}$ at age 7 , and at $0.5,1$ and $2 \mathrm{kHz}$ at age 9 and 11.

Table 5 Differences in hearing threshold between c.101T>C carriers at age 7 ( $n=171$ ), age 9 ( $n=150$ ) and age 11 ( $n=135)$ and non-carriers (unadjusted results)

\begin{tabular}{|c|c|c|c|c|c|c|c|c|c|c|}
\hline \multirow[b]{2}{*}{$\begin{array}{l}\text { Air or bone } \\
\text { conduction }\end{array}$} & \multirow[b]{2}{*}{$\begin{array}{l}\text { Frequency* } \\
(\mathbf{k H z})\end{array}$} & \multicolumn{3}{|l|}{ Age 7} & \multicolumn{3}{|l|}{ Age 9} & \multicolumn{3}{|c|}{ Age 11} \\
\hline & & $\mathbf{N}$ & $\begin{array}{l}\text { Coefficient dB† } \\
(95 \% \mathrm{Cl})\end{array}$ & $\begin{array}{l}p \\
\text { Value }\end{array}$ & $\mathbf{N}$ & $\begin{array}{l}\text { Coefficient dB† } \\
(95 \% \mathrm{Cl})\end{array}$ & $\begin{array}{l}p \\
\text { Value }\end{array}$ & $\mathbf{N}$ & $\begin{array}{l}\text { Coefficient dB† } \\
(95 \% \mathrm{Cl})\end{array}$ & $\begin{array}{l}\mathbf{p} \\
\text { Value }\end{array}$ \\
\hline \multirow[t]{8}{*}{ Air } & 0.5 & 5892 & $0.30(-0.82$ to 1.42$)$ & 0.602 & 5697 & $-0.02(-1.08$ to 1.03$)$ & 0.961 & 5429 & $0.33(-0.76$ to 1.44$)$ & 0.550 \\
\hline & 1 & 6147 & $0.64(-0.49$ to 1.78$)$ & 0.266 & 5783 & $-0.40(-1.49$ to 0.68$)$ & 0.466 & 5473 & $-0.23(-1.32$ to 0.85$)$ & 0.671 \\
\hline & 2 & 6091 & $0.38(-0.71$ to 1.49$)$ & 0.491 & 5782 & $-0.38(-1.44$ to 0.67$)$ & 0.474 & 5472 & $-0.57(-1.69$ to 0.55$)$ & 0.318 \\
\hline & $3 \ddagger$ & & & & & & & 5431 & $-0.74(-1.87$ to 0.38$)$ & 0.194 \\
\hline & 4 & 6144 & $0.36(-0.89$ to 1.61$)$ & 0.572 & 5782 & $0.25(-0.95$ to 1.46$)$ & 0.678 & 5468 & $0.45(-0.74$ to 1.65$)$ & 0.457 \\
\hline & $6 \ddagger$ & & & & & & & 5427 & $0.33(-1.06$ to 1.72$)$ & 0.641 \\
\hline & 8 & 6119 & $-0.58(-1.99$ to 0.83$)$ & 0.422 & 5675 & $0.02(-1.44$ to 1.49$)$ & 0.971 & 5458 & $-0.55(-2.04$ to 0.92$)$ & 0.462 \\
\hline & $16 \S$ & 2860 & $3.25(-0.25$ to 6.75$)$ & 0.069 & 4166 & 7.61 (4.26 to 10.96$)$ & 0.000 & & & \\
\hline \multirow[t]{4}{*}{ Boneף } & 0.5 & & & & 5581 & $0.26(-0.81$ to 1.33$)$ & 0.635 & 5444 & $-0.71(-1.81$ to 0.39$)$ & 0.208 \\
\hline & 1 & 6001 & $-0.26(-1.32$ to 0.79$)$ & 0.669 & 5753 & $0.02(-1.02$ to 1.07$)$ & 0.961 & 5449 & $-0.28(-1.35$ to 0.78$)$ & 0.604 \\
\hline & 2 & & & & 5593 & $0.34(-0.84$ to 1.53$)$ & 0.569 & 5445 & $-0.72(-1.95$ to 0.50$)$ & 0.250 \\
\hline & 4 & 6107 & $0.43(-0.57$ to 1.45$)$ & 0.396 & & & & & & \\
\hline
\end{tabular}

${ }^{*}$ Right and left ear average.

$\dagger$ positive coefficient means that hearing threshold is higher (ie, worse) in the carrier group compared to the non-carriers.

†Thresholds at 3 and $6 \mathrm{kHz}$ were measured at age 11.

$\S$ Thresholds at $16 \mathrm{kHz}$ were measured at age 7 and 9 .

१Bone conduction thresholds were measured at 1 and $4 \mathrm{kHz}$ at age 7 and at $0.5,1$ and $2 \mathrm{kHz}$ at age 9 and 11 . 
and 11 years, consistent with the smaller study of Engel-Yeger et $a l^{22}$ Unlike the study by Franzé $e t a 2^{4}$ we did not show a difference in hearing at 6 and $8 \mathrm{kHz}$. Their study selected participants from a clinical caseload and were older than the participants in this study, which may account for the different results.

However at age 7 and 9 years a measure of extra-high-frequency hearing at $16 \mathrm{kHz}$ was available and comparison of the hearing thresholds at this frequency showed c.35delG carriers had hearing thresholds approximately $5-10 \mathrm{~dB}$ worse than non-carriers. There was a larger difference at age 9 than at age 7 , suggesting a worsening in extra-high-frequency hearing between these ages. This provides evidence of early changes to the hearing of the carrier group, which although not detectable on conventional audiometry may be a predictor of later changes in hearing in adulthood.

In addition, there was also evidence that OAE amplitude is lower in the c.35delG carrier group: at age 9 , the mean OAE amplitude of carriers was $2-5 \mathrm{~dB}$ lower than non-carriers with the largest differences observed at $4 \mathrm{kHz}$. At age 11, these differences were still apparent, although smaller than at age 9, possibly as a result of fewer cases in the analysis at 11 . The poorer hearing thresholds at $16 \mathrm{kHz}$ in the carrier group may explain the lower OAE amplitude, as variation in high- and extra-high-frequency hearing has been shown to explain differences in lower frequency OAE amplitude. ${ }^{34-36}$ The results could also be explained by subclinical damage to the lower-frequency regions of the cochlea not yet detectable on the audiogram.

\section{Hearing thresholds and otoacoustic emissions in $\mathrm{C.101T}>\mathrm{C}$ carriers}

Hearing thresholds and OAE amplitude were examined for the c.101T $>C$ carriers. There was no evidence of an effect of carrier status on hearing thresholds at the conventional frequencies at age 7,9 or 11 years. Examination of the $16 \mathrm{kHz}$ extra-high-frequency hearing threshold showed that those carrying c.101T $>$ C had worse hearing at age 7 and 9. The size of the effect increased from 3 to $7 \mathrm{~dB}$ between these ages. These results were similar to those obtained for the c.35delG carriers, although with weak evidence of a smaller effect.

For the OAE results, the evidence was generally weak that amplitude was lower in the carrier group. At age 9, the $4 \mathrm{kHz}$ amplitude was $1-2 \mathrm{~dB}$ smaller in the carrier group but this effect was reduced at age 11. These results suggest that the smaller differences in extra-high-frequency hearing have a negligible effect on the lower-frequency OAE and suggest that c.101T $>\mathrm{C}$ has a weaker effect on hearing than carrying c.35delG, which would be consistent with its effects in individuals homozygous for c.101T $>$ C. There has been controversy in the literature as to whether c.101T $>\mathrm{C}$ has an influence on hearing and many c.101T $>\mathrm{C}$ homozygotes and compound heterozygotes have milder hearing loss than that observed with truncating mutations such as

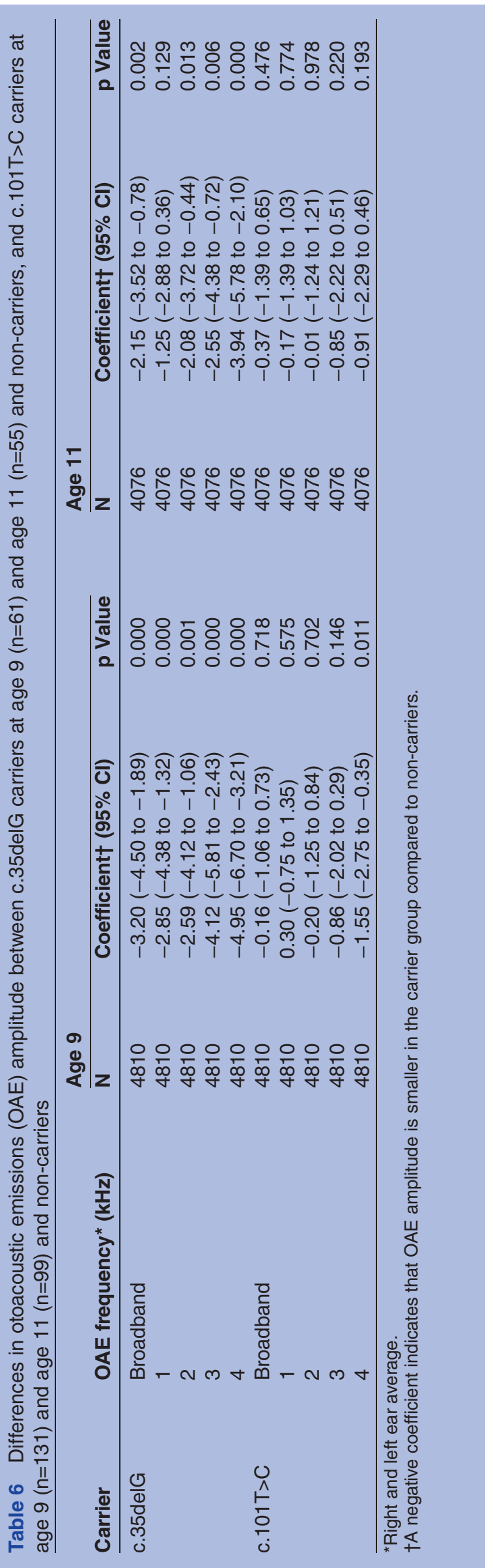


c. $35 \mathrm{delG}^{20}$ or even normal hearing. The milder effects we observe here might also suggest reduced penetrance and/or a later age of onset on hearing as suggested by others. $^{11}$

\section{Study limitations}

The sample was more advantaged than the whole of the ALSPAC cohort, as is typical with longitudinal studies of health and development ${ }^{37}$ but this should not distort specific genotype-phenotype associations. Owing to the low numbers of non-white children within ALSPAC, ${ }^{28}$ the results are generalisable to the white UK population only.

The weaknesses of this study include sample attrition and thus possible loss of statistical power to detect differences between the carriers and non-carriers, particularly for the smaller c.35delG carrier group. Not all the carrier group had hearing tests performed at each of the time points and so it is possible that we did not have the power to detect differences at the conventional audiometric frequencies. The number of cases available for the OAE analysis was smaller than those available for the hearing analysis, and thus power is equally an issue for these data.

\section{CONCLUSIONS}

We have shown that carriers of the c.35delG mutation and c.101T $>\mathrm{C}$ have subtle differences in their audiological profile at age 9 compared to non-carriers at the extra-high frequencies. This adds further evidence that c.101T $>\mathrm{C}$ is a mild but functional variant with the effect larger in the c.35delG group. It will be interesting to observe whether effects become more pronounced with advancing age.

Acknowledgements We are extremely grateful to all the families who took part in this study, the midwives for their help in recruiting them, and the whole ALSPAC team, which includes interviewers, computer and laboratory technicians, clerical workers, research scientists, volunteers, managers, receptionists and nurses. We are also grateful for the ongoing support of Professor Jean Golding throughout the study. This publication is the work of the authors and Amanda Hall and Maria Bitner-Glindzicz will serve as guarantors for the contents of this paper.

Contributors MP, MB-G and AH designed the study. AH took the lead in analysis, writing and submission. MP and MB-G provided genetics expertise. $M L$ analysed the otoacoustic emission data and advised on audiological measures. CS advised on statistical analysis. All authors were involved in drafting, revising and agreeing the final version of the article.

Funding This research was specifically funded by Deafness Research UK. The UK Medical Research Council (Grant ref: 74882) the Wellcome Trust (Grant ref: 076467) and the University of Bristol provide core support for ALSPAC. MB-G is supported by Great Ormond Street Hospital Children's Charity.

Competing interests None.

Ethics approval ALSPAC Law and Ethics Committee and Local Research Ethics Committees.

Provenance and peer review Not commissioned; externally peer reviewed.

\section{REFERENCES}

1. Kelsell DP, Dunlop J, Stevens HP, et al. Connexin 26 mutations in hereditary non-syndromic sensorineural deafness. Nature 1997;387:80-3.

2. Kikuchi T, Kimura RS, Paul DL, et al. Gap junction systems in the mammalian cochlea. Brain Res Brain Res Rev 2000;32:163-6.

3. Zelante L, Gasparini P, Estivill X, et al. Connexin26 mutations associated with the most common form of non-syndromic neurosensory autosomal recessive deafness (DFNB1) in Mediterraneans. Hum Mol Genet 1997;6:1605-9.

4. Estivill $X$, Fortina $P$, Surrey $S$, et al. Connexin-26 mutations in sporadic and inherited sensorineural deafness. Lancet 1998;351:394-8.

5. Mahdieh N, Rabbani B. Statistical study of 35delG mutation of GJB2 gene: a meta-analysis of carrier frequency. Int $J$ Audiol 2009;48:363-70.

6. Gasparini P, Rabionet R, Barbujani G, et al. High carrier frequency of the 35 delG deafness mutation in European populations. Genetic Analysis Consortium of GJB2 35delG. Eur J Hum Genet 2000;8:19-23.

7. Common JE, Di WL, Davies D, et al. Further evidence for heterozygote advantage of GJB2 deafness mutations: a link with cel survival. J Med Genet 2004;41:573-5.

8. D'Adamo P, Guerci VI, Fabretto A, et al. Does epidermal thickening explain GJB2 high carrier frequency and heterozygote advantage? Eur J Hum Genet 2009;17:284-6.

9. Green GE, Scott DA, McDonald JM, et al. Carrier rates in the Midwestern United States for GJB2 mutations causing inherited deafness. JAMA 1999;281:2211-16.

10. Houseman MJ, Ellis LA, Pagnamenta A, et al. Genetic analysis of the connexin-26 M34T variant: identification of genotype M34T/ M34T segregating with mild-moderate non-syndromic sensorineural hearing loss. J Med Genet 2001;38:20-5.

11. Pollak A, Skorka A, Mueller-Malesinska M, et al. M34T and V37I mutations in GJB2 associated hearing impairment: evidence for pathogenicity and reduced penetrance. Am J Med Genet $A$ 2007;143A:2534-43.

12. Kenna MA, Feldman HA, Neault MW, et al. Audiologic phenotype and progression in GJB2 (Connexin 26) hearing loss. Arch Otolaryngol Head Neck Surg 2010;136:81-7.

13. Martin PE, Coleman SL, Casalotti SO, et al. Properties of connexin26 gap junctional proteins derived from mutations associated with non-syndromal heriditary deafness. Hum Mol Genet 1999;8:2369-76.

14. Thonnissen $\mathrm{E}$, Rabionet $\mathrm{R}$, Arbones ML, et al. Human connexin26 (GJB2) deafness mutations affect the function of gap junction channels at different levels of protein expression. Hum Genet 2002;111:190-7.

15. Bicego M, Beltramello M, Melchionda S, et al. Pathogenetic role of the deafness-related M34T mutation of Cx26. Hum Mol Genet 2006;15:2569-87.

16. White TW, Deans MR, Kelsell DP, et al. Connexin mutations in deafness. Nature 1998;394:630-1.

17. Griffith AJ. Genetic analysis of the connexin-26 M34T variant. J Med Genet 2001;38:E24.

18. Griffith AJ, Friedman TB. Auditory function and the M34T allele of connexin 26. Arch Otolaryngol Head Neck Surg 2002;128:94.

19. Feldmann D, Denoyelle F, Loundon N, et al. Clinical evidence of the nonpathogenic nature of the M34T variant in the connexin 26 gene. Eur J Hum Genet 2004;12:279-84.

20. Snoeckx RL, Huygen PL, Feldmann D, et al. GJB2 mutations and degree of hearing loss: a multicenter study. Am J Hum Genet 2005;77:945-57.

21. Morell RJ, Kim HJ, Hood LJ, et al. Mutations in the connexin 26 gene (GJB2) among Ashkenazi Jews with nonsyndromic recessive deafness. N Engl J Med 1998;339:1500-5.

22. Engel-Yeger B, Zaaroura S, Zlotogora J, et al. The effects of a connexin 26 mutation-35delG-on oto-acoustic emissions and brainstem evoked potentials: homozygotes and carriers. Hear Res 2002;163:93-100.

23. Engel-Yeger B, Zaaroura S, Zlotogora J, et al. Otoacoustic emissions and brainstem evoked potentials in compound carriers of connexin 26 mutations. Hear Res 2003;175:140-51.

24. Franzé A, Caravelli A, Di Leva F, et al. Audiometric evaluation of carriers of the connexin 26 mutation 35delG. Eur Arch Otorhinolaryngol 2005;262:921-4.

25. Cucci RA, Prasad S, Kelley PM, et al. The M34T allele variant of connexin 26. Genet Test 2000;4:335-44.

26. Van Eyken E, Van Laer L, Fransen E, et al. The contribution of GJB2 (Connexin 26) 35delG to age-related hearing impairment and noise-induced hearing loss. Otol Neurotol 2007;28:970-5. 
27. Golding J, Pembrey M, Jones R, et al. ALSPAC—-the Avon Longitudinal Study of Parents and Children I. Study methodology. Paediatr Perinat Epidemiol 2001;15:74-87.

28. Boyd R, Golding J, Macleod J, et al. Cohort profile: the 'Children of the 90s'-the index offspring of the Avon Longitudinal Study of Parents and Children. Int J Epidemiol 2012;April:1-17.

29. Jones R, Ring S, Tyfield L, et al. A new DNA resource: a DNA bank established as part of the Avon Longitudinal Study of Pregnancy and Childhood (ALSPAC). Eur J Hum Genet 2000;8:653-60.

30. International Organisation for Standardisation (ISO). Acoustics: reference zero for the calibration of audiometric equipment, Part 1: reference equivalent threshold sound pressure levels for pure tones and supra-aural earphones. ISO 1998:389:1. Geneva: ISO.

31. British Society of Audiology Recommended Procedure. Pure tone air and bone conduction threshold audiometry with and without masking and determination of uncomfortable loudness levels. 2004.
32. Lapsley Miller JA, Marshall L, Heller LM. A Iongitudinal study of changes in evoked otoacoustic emissions and pure-tone thresholds as measured in a hearing conservation program. Int $J$ Audol 2004:43:307-22.

33. Teek R, Kruustük K, Zordania R, et al. Prevalence of c.35delG and p.M34T mutations in the GJB2 gene in Estonia. Int $J$ Pediatr Otorhinolaryngol 2010;74:1007-12.

34. Avan P, Elbez M, Bonfils P. Click-evoked otoacoustic emissions and the influence of high-frequency hearing losses in humans. J Acoust Soc Am 1997;101:2771-7.

35. Murnane OD, Kelly JK. The effects of high-frequency hearing loss on low-frequency components of the click-evoked otoacoustic emission. J Am Acad Audiol 2003;14:525-33.

36. Groh D, Pelanova J, Jilek M, et al. Changes in otoacoustic emissions and high-frequency hearing thresholds in children and adolescents. Hear Res 2006;212:90-8.

37. Young AF, Powers JR, Bell SL. Attrition in longitudinal studies: who do you lose? Aust NZ J Public Health 2006;30:353-61. 